\title{
In Surgical Treatment of Non-Small-Cell Lung Cancer a Minimum Number of Resected Mediastinal Lymph Nodes Is Mandatory for Accurate Staging
}

\author{
Armin Kolb*, Elena Steidele, Craig Matthews, Johannes Merk, Karl-Heinz Orend, \\ Bernd Mühling \\ Department of Cardiothoracic and Vascular Surgery, University of Ulm, UIm, Germany \\ Email: ${ }^{*}$ armin.kolb@gmx.de
}

Received 17 August 2014; revised 15 September 2014; accepted 10 October 2014

Copyright (C) 2014 by authors and Scientific Research Publishing Inc.

This work is licensed under the Creative Commons Attribution International License (CC BY). http://creativecommons.org/licenses/by/4.0/

\section{(c) (i) Open Access}

\begin{abstract}
Objective: Increased numbers of removed lymph nodes (LN) are resulting in more accurate staging of the patient (Will-Rogers-Phenomenon). This study evaluates dependence of lymph node sample size to 1) Will-Rogers-Phenomenom, 2) influence of sample size on overall survival and in terms of 3) morbidity and mortality. Methods: 131 patients after pulmonary resection were retrospectively analysed concerning surgery, number of removed lymph nodes, stage, complications and survival. Patients were stratified according to the median number of lymph nodes in two groups ( $A<12$ lymph nodes and $B \geq 12$ lymph nodes). Results: $5 \%$ of the patients had only local lymphadenectomy and in $14 \%$ a systematic lymphadenectomy was performed. $17 \%$ of the patients showed skip metastasis. Lymph node positivity was correlated to the number of removed lymph nodes ( $p=0.003$ ). The approximated median survival for UICC (Union internationale contre le cancer) stage I was 511, stage II 521 and stage III 290 days. Subgroup analysis of survival data showed in group $A$ an approximated median survival at stage I of 495 days, at II 537 days and at III 451.5 days. Group B showed at stage I 675 days, at II 521 days and at III 221 days. There was no difference in complications and mortality. Conclusion: A too low sample size leads to understaging due to skip metastasis. Obligatory mediastinal lymph node sampling would decrease the risk of understaging due to skip metastasis and does not increase morbidity or complications. Lymph node sampling is not inferior concerning morbidity and survival in our patient collective. This study cannot recommend a minimum number of LN to be resected. The evaluated limit of 12 LN proves to be suitable as a guideline.
\end{abstract}

${ }^{*}$ Corresponding author.

How to cite this paper: Kolb, A., Steidele, E., Matthews, C., Merk, J., Orend, K.-H. and Mühling, B. (2014) In Surgical Treatment of Non-Small-Cell Lung Cancer a Minimum Number of Resected Mediastinal Lymph Nodes Is Mandatory for Accurate Staging. Surgical Science, 5, 471-478. http://dx.doi.org/10.4236/ss.2014.510072 


\section{Keywords}

\section{Lung Cancer Surgery, Lymph Node, Lymphadenectomy, Lymph Node Sampling, Systematic Lymphadenectomy, Nsclc, Non-Small-Cell Lung Cancer}

\section{Introduction}

Non small cell lung cancer (NSCLC) is characterized as a highly aggressive and early metastasizing malignant disease [1]. Staging is a complex and critical event, as clinical staging describes the extent of the disease, predicts prognosis and is crucial for optimal treatment and outcome of the patients [2] [3]. Accuracy of clinical staging before surgery in the pre PET-CT (positron emission tomography-computed tomography) era has been reported being only 35\% - 55\% [4] [5]. PET-CT has improved the diagnostic accuracy in the staging of NSCLC [6] [7]. However, the accuracy of PET-CT is still too low to replace invasive lymph node staging [8] [9]. Furthermore, after surgical treatment the lymph node status of the patient is important as to whether adjuvant treatment modalities are mandatory.

The benefits of a radical lymphadenectomy remain controversial. Studies comparing the outcome of NSCLC patients after surgical treatment with lymph node sampling versus radical lymphadenectomy revealed contradictory results [10]. Retrospective studies found a benefit in survival for UICC stage I patients [11] [12] whereas other analyses showed no advantage for either procedure [13]-[15]. In contrast to this survival benefit, increased perioperative morbidity and mortality due to extended lymph node dissection are discussed. A different study design counting total number of extirpated lymph nodes found a correlation with improved overall survival and increased disease free interval [15]. Those results were interpreted with the "Will-Rogers-Phenomenon", increased number of removed lymph nodes resulting in more accurate staging of the patient [16] [17].

Due to the lack of meaningful randomized controlled studies, there is no international consensus. In the US the systematic lymphadenectomy is prevalent. In Japan an extended lymphadenectomy to cervical and contralateral mediastinal lymph nodes was supported. In Europe, especially in the United Kingdom and in Germany, lymph node sampling was propagated by the majority. Berardi et al. already postulated at the American Society of Clinical Oncology (ASCO) 2011 annual meeting an adequate lymph node clearance with a minimum of 10 in order to receive an adequate staging [18].

This analysis evaluates the outcome, morbidity and mortality of patients after pulmonary resection due to NSCLC based on the number and location of removed lymph nodes from the approach of the Will-RogersPhenomenon.

\section{Material and Methods}

From January 2006 through December 2010, 156 patients underwent surgery due to NSCLC in our department. 25 patients with carcinoma in situ, stage IV disease or neoadjuvant treatment were excluded from this analysis. The data of the remaining 131 patients was reviewed retrospectively from our records and analyzed in terms of surgery performed, number and level of removed lymph nodes (LN), pathological finding and stage, perioperative complications and mortality and survival data. Statistical analysis was performed using SPSS version 16.0 (SPSS Inc, Chicago, Illinois). Categorical variables were compared using $\mathrm{X}^{2}$-Test and Fisher's Exact Test. All continuous variables were plotted on a histogram to determine the distribution of data points and select the appropriate statistical test to compare cohorts. Parametric continuous variables were expressed as mean (SD) and compared using an independent-samples t-test. Nonparametric continuous variables were expressed as median values with ranges and compared using the Mann-Whitney-U-Test. Correlation analysis was done using Spearman's rank correlation coefficient (Spearman's rho) for non-parametric measure of statistical dependence between two variables. Survival data were assessed by the method of Kaplan-Meier.

\section{Results}

The median age of the patients was 66 years (range $42-82)$ and $76 \%(n=99)$ were male. Pathology report showed in 56\% ( $\mathrm{n}=73)$ squamous cell carcinoma, in $42 \%(\mathrm{n}=55)$ adenocarcinoma and $2 \%(\mathrm{n}=3)$ other 
NSCLC tumor entities. Surgical procedures performed were pneumonectomy $12 \%(\mathrm{n}=16)$, bilobectomy $7 \%$ (n = 9), lobectomy $72 \%(n=94)$, wedge resection $5 \%(n=7)$, sleeve resection $3 \%(n=4)$ and segmental resection $1 \%$ $(n=1)$.

The performed lymphadenectomy was decided upon by the surgeon. In $5 \%(n=6)$ of the patients a local lymphadenectomy was performed (LN taken: median 5.5, range 2 - 13), all other patients had at least one mediastinal LN removed (median 12, range 2 - 44). The pathological LN status was in 79 patients (60\%) pN0, in 31 patients (24\%) pN1, in 20 patients (15\%) pN2 and one pN3. In 4 of the 79 pN0 patients (5\%) only local lymphadenectomy without mediastinal LN sampling was performed, similar in 2 of the 31 pN1 patients (6\%). In 9 of the 52 LN positive patients (17\%) skip metastasis was found, distal LN were tumor infested whereas proximal LN were free of tumor. The analysis of Spearman's rank correlation coefficient for a connection between positive pathological LN status and number of removed LN showed that LN positivity correlates to the number of removed $\mathrm{LN}$ (rho $=0.254, \mathrm{p}=0.00343$ ). A systematic lymphadenectomy was performed in $11 \%$ of the patients $(n=14)$ (median 13.5, range 8 - 22). In 131 patients a total of 1637 LN (median 12, range 2 - 44) were collected and evaluated.

\section{Comparison $<12 \mathrm{LN}$ and $\geq 12 \mathrm{LN}$ Lymphadenectomy}

Patients were stratified according to the median number of removed $\mathrm{LN}$ in two comparable groups with 63 patients $<12 \mathrm{LN}$ (A) and 68 patients $\geq 12 \mathrm{LN}$ (B). Median age of patients in A was 67 years, in B 66 years respectively. Groups were not different in gender distribution, tumor entity and patient ASA (American Society of Anesthesiologists) classification.

Group A contained more UICC (Union internationale contre le cancer) stage I patients (p $=0.009)$, group B contained more UICC stage II patients $(p=0.004)$ and the extent of pulmonary resection was different. 6 out of $7(86 \%)$ wedge resections were located in $\mathrm{A}(\mathrm{p}=0.055)$ respectively 14 out of $16(88 \%)$ pneumonectomies were located in $B(p=0.002)$. The other procedures were distributed equally.

In group A, 17 patients (27\%) had only LN up to station 1 removed, in 4 patients (6\%) only a local lymphadenectomy was performed, 5 patients (8\%) were lymph node positive $(\mathrm{N}+)$. In group B 10 patients $(15 \%)$ had surgery up to station 1 lymph nodes, 2 patients (3\%) only local, 6 patients (9\%) were N+. In group A, 15 (24\%) patients were $\mathrm{N}+$, in $\mathrm{B} 36(53 \%)$ respectively $(\mathrm{p}=0.0007)$. In group A the pathological lymph node status was in 48 patients (76\%) pN0, in 8 patients (13\%) pN1 and in 7 patients (11\%) pN2. Group B had 31 patients (46\%) with pN0, 23 (34\%) pN1, 13 (19\%) pN2 and one pN3. Group A presented more pN0 patients (p = 0.0003), group B presented more $\mathrm{pN} 1$ patients $(\mathrm{p}=0.019)$, $\mathrm{pN} 2$ and $\mathrm{pN} 3$ patients were equally distributed (Table 1$)$.

Analysis of the postoperative period showed that the in-patient care duration of group A in median was 15 days (range 8 - 52) of group B 16 days (range 9 - 36): In both groups the ICU time was in median 2 days. No difference was presented between the groups. Complications and morbidity were equally distributed. Postoperative pneumothorax, pleural effusion and pneumonia presented a total of 10 occasions in group A, 13, 16 and 4 occasions in group B respectively. Blood transfusion was necessary in 10 patients in A and 13 patients in B. Pulmonary fistula was evident, 5 times in group A and 9 times in group B. All 3 re-intubations and all 3 re-operations presented in group A (Table 2).

Subgroup analysis of survival data showed patients of group A to have an approximated median survival at stage I of 495 days, at stage II of 537 days and at stage III of 451.5 days. Patients of group B showed at stage I 675 days, at stage II 521 days and at stage III 221 days. The pN0 patients of group A had an approximated median survival of 527 days, group B 5285 days, pN1 2785 days, pN1 373 days, pN2 4515 days and 216 days respectively. There was no statistical evaluation possible due to small number of patients.

The duration of in-patient care was in mean $17.5 \pm 7.2$ days (range $8-52$ ), $3.3 \pm 3.8$ days were spent on the ICU. In the perioperative period 23 patients received blood transfusions, on 26 occasions they presented with pleural effusion, 23 with residual pneumothorax, 14 cases of pneumonia, 14 fistula, on 3 occasions the patient had to be re-intubated due to respiratory insufficiency and on 3 occasions a re-operation was necessary. The perioperative in-patient care mortality was zero, in the follow up period (8 to 68 month) 34 patients (26\%) died. A median survival could not be calculated, due to lack of events for all patients and for the subgroups UICC stage I and II. The approximated median survival in total for all patients was 414 days (range 55 - 1437). For UICC stage I patients 511, for stage II 521 and stage III 290 days. There was no difference in survival between stage I and stage II ( $\mathrm{p}=0.4408)$, survival of stage III patients showed a decrease in comparison to stage I and II (p < 
Table 1. Patient data were stratified according to the median number of removed LN in two comparable groups with $<12 \mathrm{LN}$ (A) and $\geq 12$ LN (B). Differences were labeled with “*”.

\begin{tabular}{|c|c|c|c|c|c|}
\hline & & Group A & Group B & Total & $\mathrm{p}$ value \\
\hline $\mathrm{n}$ & & 63 & 68 & 131 & - \\
\hline Age (median) & & 67 & 66 & 66 & - \\
\hline \multirow[t]{2}{*}{ Gender } & Male & 43 & 56 & 99 & \multirow{2}{*}{0.069} \\
\hline & Female & 20 & 12 & 32 & \\
\hline \multirow[t]{3}{*}{ Histology } & Adenocarcinoma & 31 & 24 & 55 & \multirow{2}{*}{0.115} \\
\hline & Squamous Cell Carcinoma & 29 & 44 & 73 & \\
\hline & Other & 3 & 0 & 3 & 0.108 \\
\hline \multirow[t]{4}{*}{ ASA } & I & 1 & 1 & 2 & 1 \\
\hline & II & 9 & 8 & 17 & 0.796 \\
\hline & III & 51 & 57 & 108 & 0.819 \\
\hline & IV & 2 & 2 & 4 & 1 \\
\hline \multirow[t]{6}{*}{ Surgery } & Wedge Resection & 6 & 1 & 7 & 0.055 \\
\hline & Segmental Resection & 1 & 0 & 1 & 0.481 \\
\hline & Sleeve Resection & 3 & 1 & 4 & 0.351 \\
\hline & Lobectomy & 48 & 46 & 94 & 0.333 \\
\hline & Bilobectomy & 4 & 5 & 9 & 1 \\
\hline & Pneumonectomy & 2 & 14 & 16 & $0.002^{*}$ \\
\hline \multirow[t]{3}{*}{ UICC Stage } & I & 38 & 25 & 63 & $0.009^{*}$ \\
\hline & II & 8 & 24 & 32 & $0.004^{*}$ \\
\hline & III & 17 & 19 & 36 & 1 \\
\hline \multirow[t]{11}{*}{ Lymphadenectomy } & Local & 4 & 2 & 6 & 0.427 \\
\hline & Systematic & 5 & 9 & 14 & 0.403 \\
\hline & 1 Station & 17 & 10 & 27 & 0.089 \\
\hline & 2 Stations & 29 & 20 & 49 & 0.070 \\
\hline & 3 Stations & 13 & 22 & 35 & 0.167 \\
\hline & 4 Stations & 4 & 13 & 27 & $0.0376^{*}$ \\
\hline & 5 Stations & 0 & 2 & 2 & 0.497 \\
\hline & pNO & 48 & 31 & 79 & $0.0003^{*}$ \\
\hline & $\mathrm{pN} 1$ & 8 & 23 & 31 & $0.019^{*}$ \\
\hline & $\mathrm{pN} 2$ & 7 & 13 & 20 & 0.23 \\
\hline & pN3 & 0 & 1 & 1 & 1 \\
\hline
\end{tabular}

Table 2. Incidence of morbidity and complications. There was no difference between the groups.

\begin{tabular}{|c|c|c|c|c|}
\hline & Group A & Group B & Total & $\mathrm{p}$ value \\
\hline Pneumothorax & 10 & 13 & 23 & 0.162 \\
\hline Pleural Effusion & 10 & 16 & 26 & 0.097 \\
\hline Fistula & 5 & 9 & 14 & 0.142 \\
\hline Pneumonia & 10 & 4 & 14 & 0.058 \\
\hline Blood Transfusion & 10 & 13 & 23 & 0.162 \\
\hline Re-operation & 3 & 0 & 3 & 0.108 \\
\hline Re-intubation & 3 & 0 & 3 & 0.108 \\
\hline
\end{tabular}


0.05) (Figure 1). Dividing the patient collective in subgroups concerning the pathological nodal status pN0 patients had overall survival in median 529 days, pN1 patients 293.5 and pN2 340 days. pN0 groups overall survival was longer than $\mathrm{pN} 1(\mathrm{p}=0.0351)$ and $\mathrm{pN} 2(\mathrm{p}<0.0001)$. There was no difference between $\mathrm{pN} 2$ and $\mathrm{pN} 3$ patients (Figure 2).

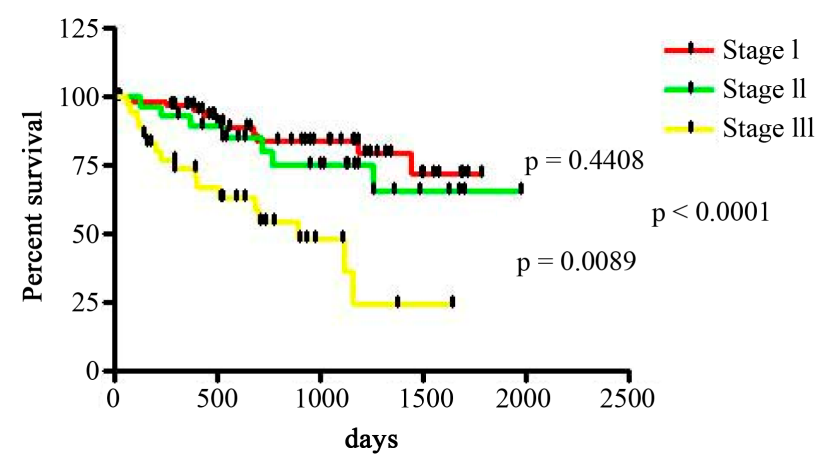

Figure 1. Median survival for UICC stage I patients was 511 days, for stage II 521 days and stage III 290 days respectively. There was no difference between stage I and stage II ( $p=0.4408)$, survival of stage III patients showed a decrease in comparison to stage I and II $(\mathrm{p}<0.0001$ and $\mathrm{p}=0.0089)$.

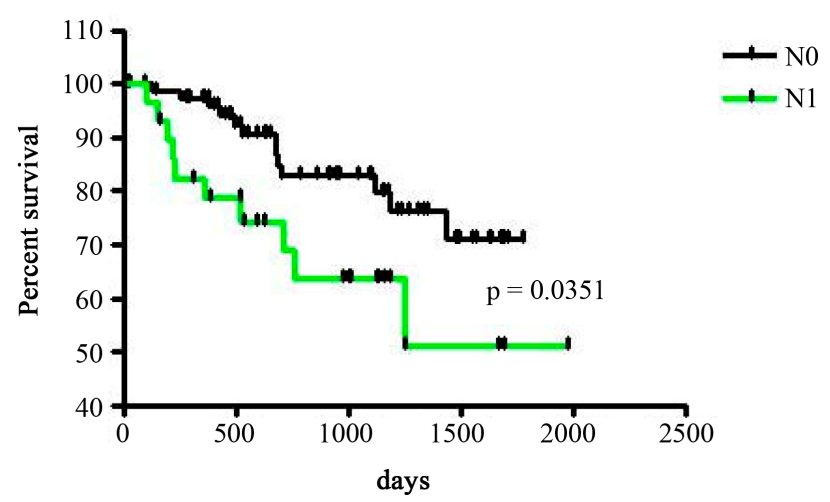

(a)

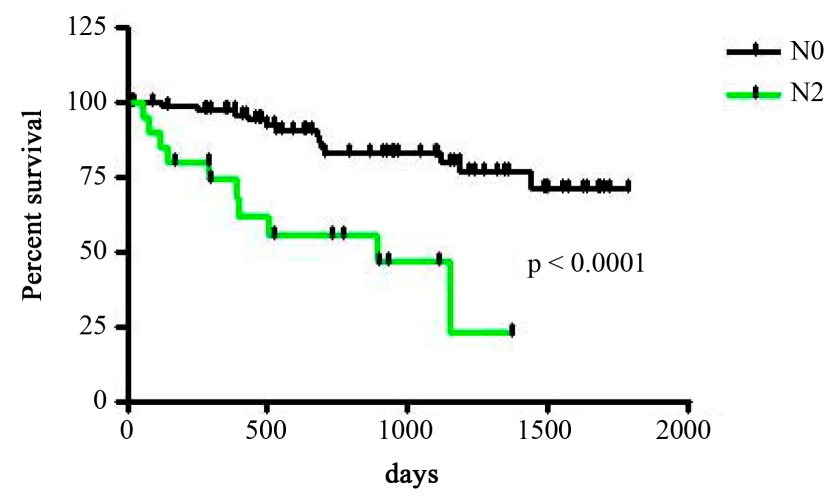

(b)

Figure 2. Dividing the patient collective in subgroups in terms of pathological lymph node status. pN0 patients had an overall survival in median 529 days, pN1 patients 293.5 and pN2 340 days. pN0 groups overall survival was longer than $\mathrm{pN} 1$ ( $\mathrm{p}=$ $0.0351)$ and $p N 2(p<0.0001)$. There was no difference between $\mathrm{pN} 2$ and $\mathrm{pN} 3$ patients. 


\section{Discussion}

Finding the answer to the important question to which extend lymphadenectomy in NSCLC patients has to be performed, the data of 131 patients consecutively operated on NSCLC was analyzed. In our study patient data showed normal distribution of gender, tumor entity and ASA classification. Also the vast majority of single lobectomy as performed surgical procedure indicates a very homogeneous cohort. The perioperative morbidity and mortality was lower compared to the literature. In similar patient cohorts perioperative mortality is reported being $1.3 \%$ - 5.6\% [19] [20]. The low number of systematic lymphadenectomies $(\mathrm{n}=14)$ may be responsible for the moderate perioperative morbidity and mortality. A statement concerning increased morbidity due to extended surgical procedure is very limited but also low in comparison [20].

All 1637 lymph nodes were allocated to their origin. In 4 out of 79 pN0 patients (5\%) and in 2 out of 31 pN1 patients (6\%) only a local lymphadenectomy was performed. A closer look at the origin sites of the tumor infested lymph nodes showed in 9 patients skip metastasis. About $17 \%$ of the tumors in our patient cohort have not continuously metastasized. Mediastinal skip lymphatic metastasis is reported in about $25 \%$ of the patients depending on the localization of the primary tumor and is important for the extent of the mediastinal lymph node dissection [21] [22]. Therefore, for these 6 patients we have to assume a certain rate of incorrect staging due to a lack of removed lymph nodes.

In addition, the present survival data suggests an inaccuracy in staging due to too low number of resected lymph nodes. This study showed no difference in overall survival between UICC stage I and stage II (511 vs. 521 days) patients. 5-year survival for stage I patients ranges between 60\% - 80\%, at stage II between 35\% - 55\% [23]-[25]. The difference to stage III (290 days) was as expected. Analysis of subgroups dividing the patient collective comparing pN0 and pN1 patients with and without mediastinal lymph node sampling presented unfortunately no difference in survival due to a very small number of events.

The patient cohort was divided according to the median number of removed LN in two comparable groups, group $\mathrm{A}<12 \mathrm{LN}$ taken and group $\mathrm{B} \geq 12 \mathrm{LN}$ removed. The number of $12 \mathrm{LN}$ as a benchmark also seemed suitable according to the postulation at ASCO 2011 annual meeting that an adequate lymph node clearance requires a minimum of $10 \mathrm{LN}$ in order to receive an adequate staging [18]. Comparing lymph node status showed increased $\mathrm{N}+$ patients in group B. Especially the pN1 subgroup presented an increase, indicating to early lymphadenopathy. Spearman rho correlation showed a connection between positive pathological LN status and number of removed lymph nodes. Higher number of removed lymph nodes increases the probability to find diseased lymph nodes. Those results correlate with the interpretation as the "Will-Rogers-Phenomenon”, increased number of removed lymph nodes resulting in more accurate staging [16] [17].

Subgroup analysis of survival data showed UICC stage I patients of group A had an approximated median survival of 495 days, patients of group B of 675 days. Survival analysis on base of pathological LN status survival curves were as expected (Figure 2). This may be a result of inaccurate staging due to a small number of lymph nodes removed for evaluation. Unfortunately, this was not statistically different due to a small number of events.

When comparing the groups regarding morbidity and complications, no difference was found. Group B was also containing mainly patients treated with lymph node sampling, only 14 patients in total had a radical lymphadenectomy. Statements to the comparable low morbidity and complications rate are very limited, but there was no difference in morbidity, complications and mortality in patients with increased lymph node sample size.

\section{Conclusion}

NSCLC is early metastasizing to lymph nodes, frequently also skipping the first lymph node station. Taking a predetermined number of lymph nodes would decrease the risk of understaging. Obligatory mediastinale lymph node sampling would decrease the risk of understaging due to skip metastasis and does not increase morbidity or complication rates. A radical lymphadenectomy would eliminate the problem of inaccurate staging, eventually in exchange to increased complication rates. This study shows limitations in finding an answer to a possible increased occurrence of perioperative morbidity and mortality due to radical lymphadenectomy. Furthermore, this study cannot recommend a minimum number of LN to be resected. The evaluated limit of 12 LN proves to be suitable as a guideline.

\section{Conflict of Interest}

None declared. 


\section{References}

[1] Siegel, R., DeSantis, C., Virgo, K., Stein, K., Mariotto, A., Smith, T., Cooper, D., Gansler, T., Lerro, C., Fedewa, S., Lin, C., Leach, C., Cannady, R.S., Cho, H., Scoppa, S., Hachey, M., Kirch, R., Jemal, A. and Ward, E. (2012) Cancer treatment and survivorship statistics, 2012. CA: A Cancer Journal for Clinicians, 62, 220-241. http://dx.doi.org/10.3322/caac.21149

[2] Spira, A. and Ettinger, D.S. (2004) Multidisciplinary Management of Lung Cancer. The New England Journal of Medicine, 350, 379-392. http://dx.doi.org/10.1056/NEJMra035536

[3] Muehling, B., Wehrmann, C., Oberhuber, A., Schelzig, H., Barth, T. and Orend, K.H. (2012) Comparison of Clinical and Surgical-Pathological Staging in IIIA Non-Small Cell Lung Cancer Patients. Annals of Surgical Oncology, 19, 89-93. http://dx.doi.org/10.1245/s10434-011-1895-9

[4] Cetinkaya, E., Turna, A., Yildiz, P., Dodurgali, R., Bedirhan, M.A., Gurses, A. and Yilmaz, V. (2002) Comparison of Clinical and Surgical-Pathologic Staging of the Patients with Non-Small Cell Lung Carcinoma. European Journal Cardio-Thoracic Surgery, 22, 1000-1005. http://dx.doi.org/10.1016/S1010-7940(02)00581-X

[5] Lopez-Encuentra, A., Garcia-Lujan, R., Rivas, J.J., Rodriguez-Rodriguez, J., Torres-Lanza, J. and Varela-Simo, G. (2005) Comparison between Clinical and Pathologic Staging in 2,994 Cases of Lung Cancer. The Annals of Thoracic Surgery, 79, 974-979; discussion 979. http://dx.doi.org/10.1016/j.athoracsur.2004.06.004

[6] Cerfolio, R.J., Ojha, B., Bryant, A.S., Raghuveer, V., Mountz, J.M. and Bartolucci, A.A. (2004) The Accuracy of Integrated PET-CT Compared with Dedicated Pet Alone for the Staging of Patients with Nonsmall Cell Lung Cancer. The Annals of Thoracic Surgery, 78, 1017-1023. http://dx.doi.org/10.1016/j.athoracsur.2004.02.067

[7] Lardinois, D., Weder, W., Hany, T.F., Kamel, E.M., Korom, S., Seifert, B., von Schulthess, G.K. and Steinert, H.C. (2003) Staging of Non-Small-Cell Lung Cancer with Integrated Positron-Emission Tomography and Computed Tomography. The New England Journal of Medicine, 348, 2500-2507. http://dx.doi.org/10.1056/NEJMoa022136

[8] Gonzalez-Stawinski, G.V., Lemaire, A., Merchant, F., O’Halloran, E., Coleman, R.E., Harpole, D.H. and D’Amico, T.A. (2003) A Comparative Analysis of Positron Emission Tomography and Mediastinoscopy in Staging Non-Small Cell Lung Cancer. The Journal of Thoracic and Cardiovascular Surgery, 126, 1900-1905. http://dx.doi.org/10.1016/S0022-5223(03)01036-5

[9] Tournoy, K.G., Maddens, S., Gosselin, R., Van Maele, G., van Meerbeeck, J.P. and Kelles, A. (2007) Integrated FDGPET/CT Does Not Make Invasive Staging of the Intrathoracic Lymph Nodes in Non-Small Cell Lung Cancer Redundant: A Prospective Study. Thorax, 62, 696-701. http://dx.doi.org/10.1136/thx.2006.072959

[10] Barnard, J., Dunning, J., Musleh, G. and Odom, N. (2004) Is There a Role for the Use of Radical Lymph Node Dissection in the Surgical Management of Resectable Non-Small Cell Lung Cancer? Interactive Cardiovascular and Thoracic Surgery, 3, 294-299. http://dx.doi.org/10.1016/j.icvts.2003.12.004

[11] Wu, Y.L., Huang, Z.F., Wang, S.Y., Yang, X.N. and Ou, W. (2002) A Randomized Trial of Systematic Nodal Dissection in Resectable Non-Small Cell Lung Cancer. Lung Cancer, 36, 1-6. http://dx.doi.org/10.1016/S0169-5002(01)00445-7

[12] Doddoli, C., Aragon, A., Barlesi, F., Chetaille, B., Robitail, S., Giudicelli, R., Fuentes, P. and Thomas, P. (2005) Does the Extent of Lymph Node Dissection Influence Outcome in Patients with Stage I Non-Small-Cell Lung Cancer? European Journal Cardio-Thoracic Surgery, 27, 680-685. http://dx.doi.org/10.1016/j.ejcts.2004.12.035

[13] Izbicki, J.R., Thetter, O., Habekost, M., Karg, O., Passlick, B., Kubuschok, B., Busch, C., Haeussinger, K., Knoefel, W.T., Pantel, K. and Schweiberer, L. (1994) Radical Systematic Mediastinal Lymphadenectomy in Non-Small Cell Lung Cancer: A Randomized Controlled Trial. British Journal of Surgery, 81, 229-235. http://dx.doi.org/10.1002/bjs.1800810223

[14] Sugi, K., Nawata, K., Fujita, N., Ueda, K., Tanaka, T., Matsuoka, T., Kaneda, Y. and Esato, K. (1998) Systematic Lymph Node Dissection for Clinically Diagnosed Peripheral Non-Small-Cell Lung Cancer Less than $2 \mathrm{~cm}$ in Diameter. World Journal of Surgery, 22, 290-294; Discussion 294-295. http://dx.doi.org/10.1007/s002689900384

[15] Lardinois, D., Suter, H., Hakki, H., Rousson, V., Betticher, D. and Ris, H.B. (2005) Morbidity, Survival, and Site of Recurrence after Mediastinal Lymph-Node Dissection versus Systematic Sampling after Complete Resection for Non-Small Cell Lung Cancer. The Annals of Thoracic Surgery, 80, 268-274; Discussion 274-275.

[16] Gajra, A., Newman, N., Gamble, G.P., Kohman, L.J. and Graziano, S.L. (2003) Effect of Number of Lymph Nodes Sampled on Outcome in Patients with Stage I Non-Small-Cell Lung Cancer. Journal of Clinical Oncology, 21, 10291034. http://dx.doi.org/10.1200/JCO.2003.07.010

[17] Ludwig, M.S., Goodman, M., Miller, D.L. and Johnstone, P.A. (2005) Postoperative Survival and the Number of Lymph Nodes Sampled during Resection of Node-Negative Non-Small Cell Lung Cancer. Chest, 128, 1545-1550. http://dx.doi.org/10.1378/chest.128.3.1545 
[18] Berardi, R., Onofri, A., Savini, A., Caramanti, M., Chiorrini, S., Santinelli, A., Brunelli, A., Zuccatosta, L., Mazzanti, P., Pierantoni, C., Scartozzi, M., Sabbatini, A., Gasparini, S. and Cascinu, S. (2011) Relationship of Number of Resected Lymph Nodes in Early-Stage Non-Small Cell Lung Cancer (NSCLC) and Survival. Journal of Clinical Oncology, 29.

[19] Allen, M.S., Darling, G.E., Pechet, T.T., Mitchell, J.D., Herndon II, J.E., Landreneau, R.J., Inculet, R.I., Jones, D.R., Meyers, B.F., Harpole, D.H., Putnam Jr., J.B. and Rusch, V.W. (2006) Morbidity and Mortality of Major Pulmonary Resections in Patients with Early-Stage Lung Cancer: Initial Results of the Randomized, Prospective ACOSOG Z0030 Trial. The Annals of Thoracic Surgery, 81, 1013-1019. http://dx.doi.org/10.1016/j.athoracsur.2005.06.066

[20] Handy Jr., J.R., Asaph, J.W., Skokan, L., Reed, C.E., Koh, S., Brooks, G., Douville, E.C., Tsen, A.C., Ott, G.Y. and Silvestri, G.A. (2002) What Happens to Patients Undergoing Lung Cancer Surgery? Outcomes and Quality of Life before and after Surgery. Chest, 122, 21-30. http://dx.doi.org/10.1378/chest.122.1.21

[21] Ilic, N., Petricevic, A., Arar, D., Kotarac, S., Banovic, J., Ilic, N.F., Tripkovic, A. and Grandic, L. (2007) Skip Mediastinal Nodal Metastases in the IIIa/N2 Non-Small Cell Lung Cancer. Journal of Thoracic Oncology, 2, 1018-1021. http://dx.doi.org/10.1097/JTO.0b013e318158d471

[22] Okada, M., Tsubota, N., Yoshimura, M. and Miyamoto, Y. (1998) Proposal for Reasonable Mediastinal Lymphadenectomy in Bronchogenic Carcinomas: Role of Subcarinal Nodes in Selective Dissection. The Journal of Thoracic and Cardiovascular Surgery, 116, 949-953. http://dx.doi.org/10.1016/S0022-5223(98)70045-5

[23] Arriagada, R., Auperin, A., Burdett, S., Higgins, J.P., Johnson, D.H., Le Chevalier, T., Le Pechoux, C., Parmar, M.K., Pignon, J.P., Souhami, R.L., Stephens, R.J., Stewart, L.A., Tierney, J.F., Tribodet, H. and van Meerbeeck, J. (2010) Adjuvant Chemotherapy, with or without Postoperative Radiotherapy, in Operable Non-Small-Cell Lung Cancer: Two Meta-Analyses of Individual Patient Data. Lancet, 375, 1267-1277.

[24] Goldstraw, P., Ball, D., Jett, J.R., Le Chevalier, T., Lim, E., Nicholson, A.G. and Shepherd, F.A. (2011) Non-SmallCell Lung Cancer. Lancet, 378, 1727-1740. http://dx.doi.org/10.1016/S0140-6736(10)62101-0

[25] Mountain, C.F. (1997) Revisions in the International System for Staging Lung Cancer. Chest, 111, 1710-1717. http://dx.doi.org/10.1378/chest.111.6.1710 
Scientific Research Publishing (SCIRP) is one of the largest Open Access journal publishers. It is currently publishing more than 200 open access, online, peer-reviewed journals covering a wide range of academic disciplines. SCIRP serves the worldwide academic communities and contributes to the progress and application of science with its publication.

Other selected journals from SCIRP are listed as below. Submit your manuscript to us via either submit@scirp.org or Online Submission Portal.
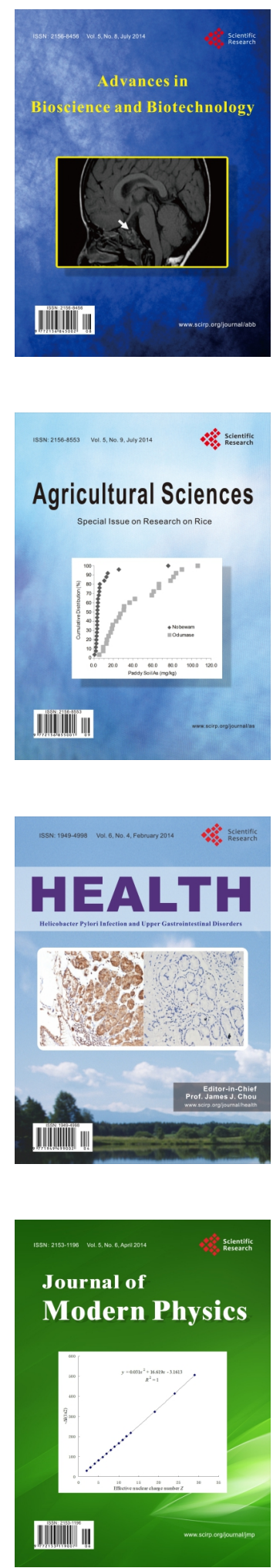
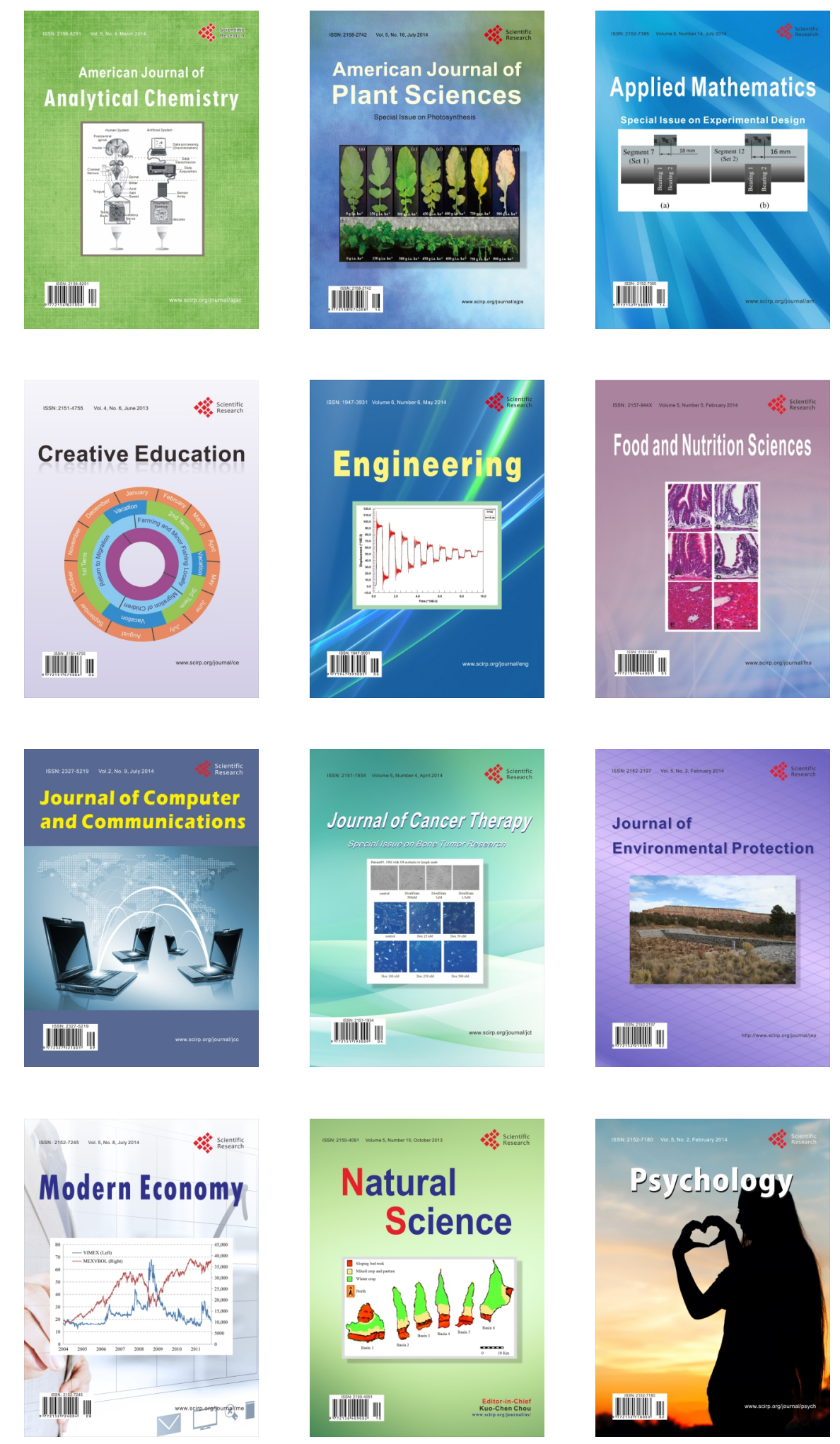